\title{
CONCEPTUAL MODEL OF THE CAREER PATH BETWEEN CAREER PERFORMANCE ATTRIBUTES AND EMPLOYEE PERFORMANCE IN PUBLIC SECTOR IN OMAN
}

\author{
Salim Al Abdali \\ PhD fellow at the Faculty of Business and Accountancy (FBA) \\ University Selangor (Unisel), Shah Alam, Malaysia \\ E-mail: salim.alabdali@gmail.com
}

\author{
Abul Bashar Bhuiyan \\ Associate Professor at the Faculty of Business and Accountancy (FBA) \\ University Selangor (Unisel), Shah Alam, Malaysia \\ E-mail: bashariuk@gmail.com
}

\begin{abstract}
The aim of the present study is to review and develop a conceptual model of the relationship between career performance attributes, career path, and employee performance of the public sector in Oman. The study used online empirical recourses by the name of career performance attributes, career path, and employee performance in different online database sources such as Google Scholars, Springer Link, Wiley, Science Direct, JSTOR, Emerald full text, Scopus, and EBSCO HOST, etc. The review study summarized that Job satisfaction is the positive emotion result from the appraisal of job experience and fulfillment of employee needs. The study also found that job satisfaction can gain high performance whereas the dissatisfied performance of employees yields low employee performance. Moreover, the study also observed that career development and life changes have become very challenging for working women and there are numerous studies targeted towards gaining a better understanding of this issue, its consequences and the significance of these challenges. Finally, the research develops a conceptual framework that is to be followed in order to analyze the various elements and aspects. The framework has been designed by considering the various variables and their intricacies in particular relation to the subject matter of the research work in Oman and the regions.
\end{abstract}

Keywords: Career Performance Attributes, Career Path, Employee Performance \& Oman.

\section{INTRODUCTION}

Working environment is considerably plays an effective role in the overall performance of an employee. (Triguero Sánchez, Peña Vinces, \& Guillen, 2018) has critically argued while saying that the impact of working environment is literally immense on the overall performance of an employee, either with negative or with positive outcomes. This competitive world where the organizations debate on offering the actual rights of the employees, keeping them mentally and psychologically satisfied and engaged in the organizational development process seems to be given the priority. (Tatoglu, Glaister, \& Demirbag, 2016) has further addressed that with the advancement of the technology, employees of today are mostly needed to work indoors, use their brains more than that of concentrating on the physical works, leaving a great impact on their mental status, actions performance and overall abilities. Further, (Suleman, Hussain, \& Shehzad, 
2018) has pointed out that increased productivity and better outcomes in an organization can therefore be definitely assumed as the result of effective working environment. Effective physical environment strategically provides a booster to the employee's workability and ultimately improves the overall productivity. A number of studies like (Taamneh, Alsaad, \& Elrehail, 2018) clearly show that employee dissatisfaction, disordered workplaces and messy physical environment do have the direct role in losing of the major employee productivity that critically affects an organizational growth.

The trend of employability of the past years is evidently showing a strategic disparity between the skills of workers can offer and the actual skillsets that they originally show. This discrepancy clearly highlights that the employers demand from workers often dwindles, developing a significant void in the operational development process. (Al Busaidi, Bhuiyan, \& Zulkifli, 2019; Al Hinai, Bhuiyan, \& Husin, 2020a, 2020b, 2020c; Suleman et al., 2018) have witnessed this particular trend clearly is no strategically right path that may lead the workers to succeed and grow, and enable the organization to attain the competitive advantages. Having or not having the perfect career path mapping evidently impacts on the overall output of a research work.

Hence, concentrating on the various variables can explicitly address the provident career path in order to achieved the desired result. Speciously, one can directly point out to a number of factors those deter an individual to emerge out successful in his or her career path. For instance, when an employee works in a position for a long time, and cannot get the chance to portray his or her talent, skill or experience, definitely it makes the person face the utter stagnancy. Necessarily, it seems to have become a serious issue to understand how the strategies are required to be implemented in order to overcome the underlying challenges, and provide the employees significant chances in order to emerge out with the strategic and effectual career performance. Researchers like (Subbarayalu \& Al Kuwaiti, 2018) have importantly addressed that the challenges like excessively high employee turnover, low amount of employee satisfaction, little possibilities of personal development seem to have direct impact on the overall productivity and performance of an organization. this is the very reason that majority of the organizations of today are particularly concentrating on developing a strong and sophisticated HRM systems with particular focus on career development, effectively enabling the employees to ascent the corporate ladder according to their experience and attain the higher positions that they actually deserve to acquire or perform the responsibilities that they think would evidently suit them.

Moreover, (Shoaib \& Baruch, 2019) have stated that to ensure the highest employee satisfaction and to retain the skilled and highly competent staffs, organizations are desperately in need of applying the comprehensively effective, dynamic and strategic human resource practices and policies. For example, organizations of today are constantly considering employee rewarding system as a regular strategy to keep the workforce satisfied, attract the new skilled workforce, retain the existing workers and thereby improve the profit margin. In this way, organizations are desperately in need of a clear career path for its workforce which also enables the organization to measure the capabilities of the staffs, and lead them to enjoy the duties and responsibilities they are shouldered upon with.

\section{Working Environment}

\section{LITERATURE REVIEW}

Secured, convenient and appealing work environments can be produced only if the organizational surrounding is secured and sound. Sound organizational surrounding monitoring 
processes consists of sound monitoring, office lighting, air condition, provisions to meet the staff requirements, application of colours, work-place hygiene and offering other services needed by the staff such as toilets, wardrobe and religious places. In the context of improving employee's productivity, it is essential to explore the work-place surroundings, as it is in connection with encouragement which will lead to enhancing the all-round productivity of the employees.

As per (Shaya \& Khait, 2017), it is significant to pay attention to work surrounding because of two factors, first is the requirement of a comfortable workplace and employee's social connectivity beyond their organization. A convenient as well as sound work surrounding is managed by an organization on the basis of ethical, lawful and economical parameters. Ethically, the management of an organization maintains a secured, convenient and sound atmosphere that is created completely based on mankind. The management even conducts operations to generate useful and consistent work surroundings. Another purpose of the workplace should be to minimize incidents that can cause the employees and their families to suffer. As per (Osibanjo, Abiodun, \& Adeniji, 2014), tangible work surrounding is everything that surrounds an organization and that can influence the employees both immediately and circumstantially. Moreover, it is used by the employees to conduct their operations and also affects their ethical and emotional functions. It includes the air density, big space, sound, width and closeness affecting an individual's attitude. Also, it has the potential to put pressure on the employees that influences their productivity. Non-tangible work environment is all the conditions that exist in connection with the working relationship, including connection with the seniors as well as the juniors (Osibanjo et al., 2014).

Work surrounding can be another reason for enhancing the workforce productivity. Office convenience, presence of work assistance provisions, consistent work environment as well as a humble connection in between the workforce, senior and junior are the workplace surroundings that can lead the employees to give a higher level of performance (Raziq \& Maulabakhsh, 2015). Few factors for which an organization should pay heed to their work surrounding is that a convenient work-place surrounding will generate greater level of performance and also the absence of assisting provisions for work performance can lead to a considerable fall in the employee productivity rate (Osibanjo et al., 2014). Thus an effective office environment that assists the complete deployment of tasks has the potential to motivate greater productivity among the workforce both in terms of its magnitude as well as standard. (Samsudin, Isahak, \& Rampal, 2018) studies is related to the outcome of the exploration made by (Osibanjo et al., 2014), that work place should create an environment where employee's productivity can be enhanced. In specific circumstances, the elements that finds out the elements that an employee is contended with work he does is because of the presence of an appropriate working condition (Mulyanto, 2015). Few of such explorations have accomplished themselves experimentally to justify that work surroundings can generate work contentment among the employees. Where there is sound working conditions, the employees feel delighted and satisfied in finishing their work.

\section{Motivation}

(Shoaib \& Baruch, 2019) debates that compensating includes all kinds of fiscal earnings, concrete provisions as well as the advantages which are received by the employees as a component of their working connections. (Taamneh et al., 2018) explain the term recompensation as that received by the workforce in return to the service they offered to an organization. Also, it is considered to be a kind of award provided by an organization to their 
staff. Such recompensation can be granted in terms of fiscal remuneration as well as non-fiscal remuneration. Compensating is considered to be a key component in manpower management of an organization. It is highly essential for the two teams, that is both for the staff as well as the organization. Moreover, it acts as a channel to draw interest of the employees, manage the employees and also encourage them to put in more efforts to improve their performance. Since remuneration is a condition due to which an individual want to work, it can also contribute towards being a great reason for staff contentment (Mabaso \& Dlamini, 2018). Moreover, the above concept is also backed up by (Ismail, 2016) who depicts that both compensating and remunerating are difficult as well as multivariate elements of work contentment in senior educational organizations.

As per (Ukil, 2016), the compensating method used by organizations to pay their employees is affected by numerous elements. Such elements bring a provocation for every organization to find out about their decompensation principles for their employees. Offering compensation to the employees of both private as well as government organizations as per the proper principle under which the organization functions, is one technique to enhance the productivity of the employees. This technique is adopted because remuneration is considered to be an important reason that creates an impact of the level of staff contentment as well as the attitude of the workforce. To make it more clear, the greater is the remuneration offered to the staff, the more will be the work contentment level of the employees. Moving ahead, the greater the contentment rate of the employee, the greater will be their productivity. The explanation in the context of the connection between compensating and staff productivity is assisted by few experimental justifications that has been conducted by numerous explorers inclusive of both (Turner, 2018) and (Triguero Sánchez et al., 2018). According to both their findings it was revealed that any means of compensating employees be it fiscal or non-fiscal will result in influencing workforce productivity. Further experimental justifications states that a significant impact lies between the compensating process as well as work contentment. As per (Tatoglu et al., 2016) remuneration and perks can be reason due to which the employees will attain greater job contentment level. At the same time, (Taamneh et al., 2018) also justifies that if good remuneration is offered the employees will tend to work more effectively. Also, (Saeed et al., 2013) states that remuneration conditions like pay, wage, appreciation, advancement, effective performance greatly influences the rate of contentment of the employees. Few research studies justify that work contentment can be produced by providing effective remuneration.

\section{Social Factors}

(Martin \& Thawabieh, 2018) mentioned in their studies that the job satisfaction level among the employees is impacted by the relationship with co-workers at workplace. Regardless of other factors the employee perceives that the positive relationship at workplace because it directly impacts on individual productivity at workplace. However, there are negative relations at workplace result into low level of job satisfaction and decline in business performance. (Motlou, Singh, \& Karodia, 2016) support the research study that the social information prevailing in the business impact on job satisfaction among the employees. But the new employees at workplace can be morally corrupted at workplace during the socialization process. The employee needs to go through training and development program for employee motivation if they are around negative employees. In (Mete, Sökmen, \& Biyik, 2016) perform the research study where training video if viewed by the participants who are under assembly line workers who gave review regarding the job. The study has shown that the participants who have watched the video 
so they enjoy working tasks whereas who has performed tasks without watching any video are not motivated to perform task. The research on social information processing theory shows that the social environment doesn't have any impact on employee attitude and behaviour at workplace.

(Khan \& Markauskaite, 2018) assert that the binary work responsibilities and family along with their clashes must be proportioned in their family and work expectations as well. To succeed in international business travel by balancing the stress, the social support gives the moderator factor. The experience they gathered and the opinions they had in the week before their journey, the on-trips in foreign and post-trip after return were asked them to remember. The study analyses that social support could have been a vital managing method against the exertions from family-work confrontation and by its effect on discerned pressure and insists the person to improve stable social support resources and networking at work as well as at home. This relativity would have importance as it would receive less pressure from family as well as the company. According to most researchers, who evaluated the features of business trips consider them to be pressure for the business traveller. (Khadhuri \& Eid, 2017) in his research study, represents two mentoring epitomes. The conventional perspective of mentoring is about a more experienced person to be considered a mentor and he pursues to be the epitome for a person obtaining less experience. That person is called the mentee. From the Department of Justice, a case study has been implemented to focus on that smooth mentoring initiative. Guided learning is another initiative. A co-worker who is more experienced implements the guided learning method to teach new skills to a less experienced employee. Another case study is represented to emphasize the application of guided learning. Mentoring connectivity happens in companies informally and obtains more time to construct career progression and psycho-social activities. (Kemp \& Zhao, 2016) had his research in the United States and asserted that companies that have a larger number of women employees obtain more policies of balancing work-life. The companies which recruit more women are supposed to have greater levels of productivity with higher numbers of policies. This assertion opposes the "adverse selection theory". As per this theory, the companies which have more lucrative policies would pursue those people who are needier of those policies.

(Kemp \& Zhao, 2016) in his research paper focuses on an important yet not discussed subject that is the impact of globalization and competitiveness the multinational companies face and the function that females can obtain to address those problems. Along with the growing requirement for scarce potentials and the confrontation for management quality, lady executives could have taken part to increase organizational functioning. He initiates barrier issues to the development of women executives and illustrates that to be a worldwide leader. The MNCs should develop programs that are action-oriented to inscribe gender and variable factors and the work-life apprehension of the modern society. (Waxin \& Bateman, 2016) in their analytical study, explains that social support at the workplace can incur from the company in a large firm, the immediate administrators as well as fellow employees. When support is pursued in this way, companies address and often avoid the supportive factors by their policies, advantages, tradition, and the career trails to gain a workable proportion between family and work life. An employee apart from his/her work can obtain social support from a spouse, siblings, parents, wards, expanded family as well as friends. Partners can support themselves in different ways such as income and own economic management. 


\section{Performance Appraisal}

There are various roles and responsibilities of an HR manager that must be taken into consideration hereby. It is true that many business organizations face challenges in sustaining in the extreme level of competitive business environment. However, it is not an issue if the employees of an organization are skilled and are performing their activities effectively (Aladwan, Bhanugopan, \& Fish, 2016). In case of public limited companies, it is often understood that greater level of competition is observed and they need to have proper plans to make sure that financial and HRM activities are at stable stage for those particular companies. In this regard, the New Public Management (NPM) model must be taken into consideration. Under this particular model, government initiatives and activities must be reinvented to make sure that a particular market is more competitive in nature and there are lesser to no monopolies in any market. That is the way by which the government can make sure that all companies are getting equal opportunities and the consumers are also being charged moderately or in a cost effective manner.

It should also be noted that HR managers must be able to adopt a strategic approach to organizations so that any types of organizational issues and challenges are eliminated effectively. Apart from the HR managers, managers of different types and groups should also be able to take equal responsibilities to make sure that an organization will be free from issues (Ali, Nusair, Alani, Khan, \& Al Badi, 2017). It is necessary for organizational success. For any organization, the employees play a major role. They should be considered as the most essential asset of an organization. It is also true that skill development of the employees is necessary and accordingly, it is required that all employees are properly trained to make sure that the organizational requirements are fulfilled by them. According to (Agha, Azmi, \& Irfan, 2017), job training and performances of the employees of an organization are positively related to each other. (Subbarayalu \& Al Kuwaiti, 2018) thinks that job training, if performed carefully, can effectively create the basis of an organization. Therefore, the overall job role and performance of an employee can also be improved with the help of effective job training. (Pedrini, 2018) also has stated his opinions regarding the idea of human resource. According to him, for the growth of a business, the contributions of people are very high. Any organization cannot fulfil its goals and objectives without the presence of its skilled workforce. Every company requires the presence of some skilled employees who can effectively put efforts towards the organizational objectives in order to achieve long and short-term goals. It is also a proven fact that by providing job trainings to the employees, an organization can reduce time and hence the numbers of mistakes can also be reduced accordingly. Therefore, the needs for training the employees are must for any company. According to (Waxin \& Bateman, 2016), trainings can help in improving the skills and knowledge of the employees and as a result, their productivity and confidence increase.

(Kemp \& Zhao, 2016) highlights a major factor hereby. According to him, if training and development is performed at a lower level, then the possibility of employees to migrate to another organization may become higher. That is a challenge for companies and this factor should be taken into consideration effectively. Similarly, in the higher levels, training effectively improves the satisfaction levels of employees and they feel more committed towards the company. As a result, the chances of migrating to another company decreases. Through training and development, the performances of employees improve and they start performing more promisingly. Hence, the risk of poor performances or mistakes can reduce. Additionally, the present business environment is largely competitive in nature and organizations must formulate strategies to sustain in this extreme level of competition. Hence, training the employees 
effectively will make sure that they are capable of working hard in these extreme situations of competition. (Al-Mahdy, Emam, \& Hallinger, 2018) has also suggested that to make sure that employees of an organization are skilled and productive, it is necessary to train them. According to (Ismail, 2016), trainings must be designed in such a way that organization's as well as employees' needs are fulfilled effectively. If the training is not designed as per employees' needs, many negative consequences can be observed.

\section{METHODOLOGY}

As the aim of the present study is to evaluate the effects of the working environment, motivation and social factors on career performance in Oman. The methodology of this paper is done by conducting an extensive secondary data analysis. Therefore, the study used online empirical recourses by the name of working environment, motivation and social factors and career performance and career path development in different online database sources such as Google Scholars, Springer Link, Wiley, Science Direct, JSTOR, Emerald full text, Scopus, and EBSCO HOST, etc. The present study used most relevant articles for review and summarized all review findings to develop a conceptual model of the relationship between career performance attributes, career path, and employee performance of the public sector in Oman.

\section{SUMMARY OF FINDINGS}

The career of the professionals who are working in Oman, either in private or public organizations in a number of situations is seemed to get seriously challenged. The students who complete their study often seem to get confused which particular profession should they choose. This particular issue fundamentally makes the students, the future professionals of the country, feel frustrated which in turn demotivates them to invest their best skills, experiences and knowledge in the development of the organization they are going to be attached with in future. Most of the organizations in Oman seem to have eventually failed to provide their employees to show the corporate ladder that they can scale in order to attain the benefits and show their skills, competencies, and abilities in the strategic development of the organization. Also, the organizations are not effectively equipped with all the necessary awarding facilities that most of the organizations across the globe are considering these days. Hence, employees in majority of the Omani organizations are eventually being seen to face serious aces of frustration and in a large number of cases they remain aimless which eventually impacts on the organizational development process. This particular approach is also quite challenging for the organizations since they cannot expect the best from the employees. With better situation and opportunities being offered by other organizations, employees prefer to shift in these places which critically impacts on the operational and competitive development of the organizations. One must importantly mention this particular situation also hampers the good will of the organizations, making it difficult for them to convince the new workforce to join with them and work competently in the operational development process. This particular situation develops bad image regarding the organization which brutally impacts it in the strategic development process. It has a seriously challenging impact on the organization in the longer term.

A strategically effective, hygienic and healthy environment ensures bringing satisfaction among the employees while a drab, challenging and competitive atmosphere leaves seriously poor impact on the employees. In different times, employees are required to face a number of challenges, both operational and organisations where they are essentially expected to invest their best knowledge, skills, and experience, However, in a poorly developed atmosphere an employee 
basically refuses to invest his or her abilities which ultimately creates challenges for the organisation. Professional career of a person is dedicatedly linked to the social factors which definitely works as a motivator to move ahead in the comprehensive development process. Having an oblique working environment and with no social motivation basically a person seems to feel depressed and does not feel much interested to grow. A number of researchers henceforth have particularly concentrated on developing a healthy internal work culture that would typically ensure in the comprehensive organisational growth. The higher the employees are kept satisfied, the more they can be expected to employ their best skills and abilities in the development of the organisation. A number of researchers have found this out that maintaining a sophistically impressive working environment basically helps an organisation to maintain a good image before the pool of the skilled candidates in the market and helping it to acquire the best talents. Possibly this is the main reason that majority of the organisations across the globe are focusing on maintaining effective working atmosphere. Also, one should importantly address that the good working atmosphere keeps the employees more engaged to the organisation than that of the other and it has a significant role in the comprehensive development of the organisation.

The better an employee is able to maintain his or her career performance, the higher the skills and competencies the individual can expect to invest in the long run that helps the organization as a whole. The career performance growth has a massive role in determining the career path of an employee. Basically, when a fresher candidate looks for job, the aim of the person revolves around developing the career path which in the long run critically helps in the comprehensive development process. With high facilities, satisfactory working atmosphere within the organization, strategic operational development facilities provided to the employees and effective retention policies within an organization essentially ensure the employees growth, offering better career performance to the organization. This particular career performance also does have a role in the strategic and comprehensive career development process as well. A number of researchers have seen that the professional career process typically ensures the strategic growth of an individual employee. The higher an individual employee is able to attain the professional satisfaction, the wider the employee can invest his or her best possible knowledge in the strategic development process. The comprehensive strategic career path strategically and dynamically helps in application of skills, experiences and talents in the future development process. It also has a comprehensive role in the strategic intensity development process.

The career path is basically the professional career choice of an employee which typically constitutes employing one's skills, talents and knowledge's. A satisfactory career path of an employee mostly helps an employee remain confident and strategic in order to invest the best abilities at his or her workplace. The positive the career path, the effective the performance of a person. Evidently, this particular stride typically helps in the cohesive development of an employee. It is well known that a number of employees working in both the private and the public sector organizations across Oman are not that much satisfied which often lead them to change their career path as well. One should mandatorily mention that influence of effective career path strategy typically helps in better and comprehensive career performance process. It also has a significant role in research and innovation process a well. A typically satisfied employee can work harder. However, at Omani public sector organization in the past years the number of the total frustrated and depressed employees have increased significantly. Different researchers have shown that since the organizations fail to offer effective career development opportunities to the employees, naturally the amount of depression among them increases, 
keeping them unsatisfied in nature. Also, one should typically mention that employees, mostly the fishers are often seen to be confused in their choice of career path which let them to show poor performance, disrupting both the organizational and individual's career development process. One should accuse the poor career development ladder shown by the academic life which leads to serious challenges in the long run in the professional life. Surprisingly, a little number of organizations or academic institutions across Oman are seen to address this particular issue in the past effectively which eventually lead to deepen this problem.

The impact of career path on the career performance is literally significant which unless properly managed, leads potential challenges. Importantly career path is the choice of the professional career which is evidently required to be more strategic and dynamic in nature. This particular element comprehensively helps in employee performance development process. A satisfied employee becomes emotionally attached to the organization and works in the comprehensive development process. The organizations are therefore required to be strategic, dynamic and iterative in nature so that they can understand the employee demands and expectations effectively, and work comprehensively in order to offer them with the same so that loyalty of the employees can be ensured. Both the public sector organizations as seen by different researchers are required to make the employees work integrated and united, see each other to grow, attain the desired goals and get influenced. Evidently, this particular strategy would typically help the organizations to bring the employees in their performing paths. Ensuring the mental, psychological and social satisfaction of the employees seems to have become literally important in this competitively challenging market. The more the engagement of the employees are ensured, the higher the comprehensive employee development process be assisted. Although a number of research works have been conducted to understand about the attributes, play effective role for the employee development process, a little number of them do concentrate on career path establishment and career management approaches or analyzing the role of the attributes on the development of the employees. Hence, this particular study would definitely concentrate on this aspect. Also, it would concentrate on understanding the underlying relationships among the different factors which will help in providing better recommendations to the organizations.

\section{DEVELOPMENT OF THE CONCEPTUAL FRAMEWORK}

The present study summarized all review findings to develop a conceptual model of the relationship between career performance attributes, career path, and employee performance of the public sector in Oman. In order to do this the researcher develops a framework that is to be followed in order to analyse the various elements and aspects. The framework has been designed by considering the various variables and their intricacies in particular relation to the subject matter of the research work (refer to the following diagram). 


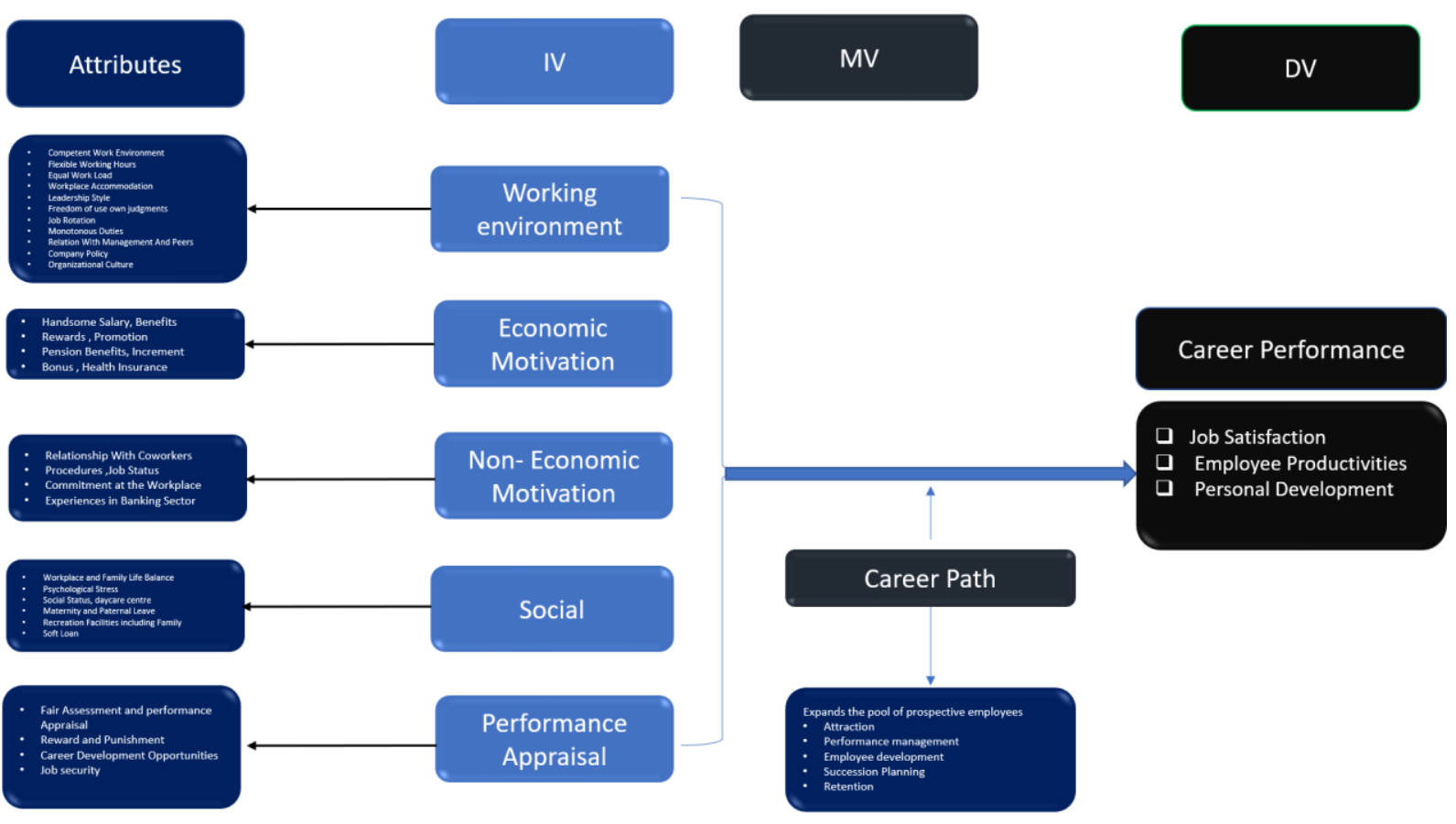

Figure 1. Conceptual model of the relationship between career performance attributes, career path, and employee performance of the public sector in Oman

\section{CONCLUSION AND RECOMMENDATIONS}

As the main aim of the present study is to review and develop a conceptual model of the relationship between career performance attributes, career path, and employee performance of the public sector in Oman. The review study summarized that Job satisfaction is the positive emotion result from the appraisal of job experience and fulfilment of employee needs. The study also found that job satisfaction can gain high performance whereas the dissatisfied performance of employees yields low employee performance. More specifically study revealed that most of the organizations in Oman seem to have eventually failed to provide their employees to show the corporate ladder that they can scale in order to attain the benefits and show their skills, competencies, and abilities in the strategic development of the organization. Also, the organizations are not effectively equipped with all the necessary awarding facilities that most of the organizations across the globe are considering these days. Hence, employees in majority of the Omani organizations are eventually being seen to face serious aces of frustration and in a large number of cases they remain aimless which eventually impacts on the organizational development process.

The study also found that the professional career of a person is dedicatedly linked to the social factors which definitely works as a motivator to move ahead in the comprehensive development process. Having an oblique working environment and with no social motivation basically a person seems to feel depressed and does not feel much interested to grow. A number of researchers henceforth have particularly concentrated on developing a healthy internal work culture that would typically ensure in the comprehensive organisational growth. The present study also indicate that the professional career process typically ensures the strategic growth of an individual employee. The higher an individual employee is able to attain the professional 
satisfaction, the wider the employee can invest his or her best possible knowledge in the strategic development process. The comprehensive strategic career path strategically and dynamically helps in application of skills, experiences and talents in the future development process. It also has a comprehensive role in the strategic intensity development process.

Different researchers have shown that since the organizations fail to offer effective career development opportunities to the employees, naturally the amount of depression among them increases, keeping them unsatisfied in nature. The impact of career path on the career performance is literally significant which unless properly managed, leads potential challenges. Importantly career path is the choice of the professional career which is evidently required to be more strategic and dynamic in nature. This particular element comprehensively helps in employee performance development process. A satisfied employee becomes emotionally attached to the organization and works in the comprehensive development process. The organizations are therefore required to be strategic, dynamic and iterative in nature so that they can understand the employee demands and expectations effectively, and work comprehensively in order to offer them with the same so that loyalty of the employees can be ensured. Both the public sector organizations as seen by different researchers are required to make the employees work integrated and united, see each other to grow, attain the desired goals and get influenced. Evidently, this particular strategy would typically help the organizations to bring the employees in their performing paths. Finally, the study also observed that career development and life changes have become very challenging for working women and there are numerous studies targeted towards gaining a better understanding of this issue, its consequences and the significance of these challenges. Finally, the research develops a conceptual framework that is to be followed in order to analyze the various elements and aspects. The framework has been designed by considering the various variables and their intricacies in particular relation to the subject matter of the research work in Oman and the regions.

\section{REFERENCES}

Agha, K., Azmi, F., \& Irfan, A. (2017). Work-life balance and job satisfaction: An empirical study focusing on higher education teachers in Oman. International Journal of Social Science and Humanity, 7(3), 164.

Al-Mahdy, Y. F. H., Emam, M. M., \& Hallinger, P. (2018). Assessing the contribution of principal instructional leadership and collective teacher efficacy to teacher commitment in Oman. Teaching and Teacher Education: An International Journal of Research and Studies, 69(1), 191-201.

Al Busaidi, N. S., Bhuiyan, A. B., \& Zulkifli, N. (2019). The Critical Review on the Adoption of ICTs in the Small and Medium Enterprises (SMEs) in the Developing Countries. International Journal of Small and Medium Enterprises, 2(2), 33-40.

Al Hinai, M. R., Bhuiyan, A. B., \& Husin, N. A. (2020a). AN EMPIRICAL REVIEW ON THE GRADUATE ATTRIBUTES AND READINESS FOR EMPLOYABILITY AMONG THE ENGINEERING GRADUATES IN THE HIGHER EDUCATION INSTITUTIONS (HEIs). Indian Journal of Finance and Banking, 4(3), 8-25.

Al Hinai, M. R., Bhuiyan, A. B., \& Husin, N. A. (2020b). THE MODERATING EFFECTS OF GENDER, CAREER, MORAL MINDSET ON THE RELATIONSHIP BETWEEN THE GRADUATE ATTRIBUTES AND READINESS FOR EMPLOYABILITY AMONG ENGINEERING COLLEGES GRADUATES IN OMAN. International Journal of Accounting \& Finance Review, 5(3), 16-30. 
Al Hinai, M. R., Bhuiyan, A. B., \& Husin, N. A. (2020c). Theoretical Review on The Graduate Attributes and The Readiness for Employability Among Engineering Graduates in The Higher Education Institutes (HEIs) in Oman. Indian Journal of Finance and Banking, 4(2), 130-139.

Aladwan, K., Bhanugopan, R., \& Fish, A. (2016). What determines the work values of employees in a Middle Eastern cultural context? Evidences from Jordanian organizations. Employee Relations.

Ali, Y., Nusair, M. M., Alani, F., Khan, F. R., \& Al Badi, L. (2017). Employment in the private sector in Oman: Sector-based approach for localization. Humanities \& Social Sciences Reviews, 5(1), 01-20.

Ismail, H. N. (2016). Training and organizational commitment: Exploring the moderating role of goal orientation in the Lebanese context. Human Resource Development International, 19(2), 152-177.

Kemp, L. J., \& Zhao, F. (2016). Influences of cultural orientations on Emirati women's careers. Personnel Review.

Khadhuri, A., \& Eid, J. (2017). An examination of the predictors of work engagement of the health care workforce in OMAN and the UAE.

Khan, M. S. H., \& Markauskaite, L. (2018). Technical and Vocational Teachers' Conceptions of ICT in the Workplace: bridging the gap between teaching and professional practice. Journal of Educational Computing Research, 56(7), 1099-1128.

Mabaso, C. M., \& Dlamini, B. I. (2018). Total rewards and its effects on organisational commitment in higher education institutions. SA Journal of Human Resource Management, 16, 8 .

Martin, A., \& Thawabieh, F. A. (2018). The Effect of ISO 9001 to Oman Higher Education Operational Performance: Buraimi University College as a Case Study. International Journal of Applied Engineering Research, 13(6), 3939-3947.

Mete, E. S., Sökmen, A., \& Biyik, Y. (2016). The relationship between organizational commitment, organizational identification, person-organization fit and job satisfaction: A research on IT employees. International Review of Management and Business Research, $5(3), 870$.

Motlou, R. G., Singh, S., \& Karodia, A. M. (2016). An evaluation of the impact of job satisfaction on employee retention at Lonmin Rowland Shaft North West province. Kuwait Chapter of the Arabian Journal of Business and Management Review, 5(10), 15.

Mulyanto, J. A. (2015). Influence of Discipline, Working Environment, Culture of Organization and Competence on Workers' Performance through Motivation, Job Satisfaction (Study in Regional Development Planning Board of Sukoharjo Regency). Regulation, 7(36).

Osibanjo, A. O., Abiodun, A. J., \& Adeniji, A. A. (2014). Impact of job environment on job satisfaction \& commitment among Nigerian nurses. Journal of South Africa Business Research, 1-11.

Pedrini, M. (2018). Exploring the effect of gender diversity in MFIs during turbulent periods. The International Journal of Human Resource Management, 29(16), 2455-2481.

Raziq, A., \& Maulabakhsh, R. (2015). Impact of working environment on job satisfaction. Procedia Economics and Finance, 23, 717-725.

Saeed, R., Mussawar, S., Lodhi, R. N., Iqbal, A., Nayab, H. H., \& Yaseen, S. (2013). Factors affecting the performance of employees at work place in the banking sector of Pakistan. Middle-East Journal of Scientific Research, 17(9), 1200-1208. 
Samsudin, E. Z., Isahak, M., \& Rampal, S. (2018). The prevalence, risk factors and outcomes of workplace bullying among junior doctors: a systematic review. European Journal of Work and Organizational Psychology, 27(6), 700-718.

Shaya, N., \& Khait, R. A. (2017). Feminizing leadership in the Middle East. Gender in Management: An International Journal.

Shoaib, S., \& Baruch, Y. (2019). Deviant behavior in a moderated-mediation framework of incentives, organizational justice perception, and reward expectancy. Journal of business ethics, 157(3), 617-633.

Subbarayalu, A. V., \& Al Kuwaiti, A. (2018). Quality of work life of teaching staff working at a higher education institution in Saudi Arabia: A cross-sectional Study. Journal of Social Service Research.

Suleman, Q., Hussain, I., \& Shehzad, S. (2018). Relation of Occupational Stress and Job Satisfaction: A Study of Secondary School Heads in Khyber Pakhtunkhwa, Pakistan. Global Social Sciences Review, 3(2), 241-274.

Taamneh, A., Alsaad, A. K., \& Elrehail, H. (2018). HRM practices and the multifaceted nature of organization performance. EuroMed Journal of Business.

Tatoglu, E., Glaister, A. J., \& Demirbag, M. (2016). Talent management motives and practices in an emerging market: A comparison between MNEs and local firms. Journal of World Business, 51(2), 278-293.

Triguero Sánchez, R., Peña Vinces, J. d. C., \& Guillen, J. (2018). How to improve firm performance through employee diversity and organisational culture.

Turner, P. (2018). Whole Workforce Development. In Talent Management in Healthcare (pp. 189-220): Springer.

Ukil, M. I. (2016). The impact of employee empowerment on employee satisfaction and service quality: Empirical evidence from financial enterprizes in Bangladesh. Verslas: teorija ir praktika, 17(2), 178-189.

Waxin, M. F., \& Bateman, R. E. (2016). Human resource management in the United Arab Emirates. In Handbook of human resource management in the Middle East: Edward Elgar Publishing.

\section{Copyrights}

Copyright for this article is retained by the author(s), with first publication rights granted to the journal. This is an open-access article distributed under the terms and conditions of the Creative Commons Attribution license (https://creativecommons.org/licenses/by/4.0). 